\title{
Influence of Coconut Fibre Inclusion on Rheological Properties of Composite Wheat-Cassava Flour Dough Using the Mixolab
}

\author{
Ibidapo Phebean Olubunmi ${ }^{1, ~ *}$, Ogunji Oluwatosin Akinyele ${ }^{1}$, Kosoko Sulaimon Babatunde ${ }^{1}$, \\ Ojo Olusola E. ${ }^{2}$, Osibanjo Adetola Adetokunbo ${ }^{1}$, Elemo Gloria N. ${ }^{1}$ \\ ${ }^{1}$ Department of Food Technology, Federal Institute of Industrial Research, Oshodi, Lagos, Nigeria \\ ${ }^{2}$ Department of Project Development \& Design Federal Institute of Industrial Research, Oshodi, Lagos, Nigeria
}

Email address:

kayibidapo@yahoo.com (I. P. Olubunmi)

\section{To cite this article:}

Ibidapo Phebean Olubunmi, Ogunji Oluwatosin Akinyele, Kosoko Sulaimon Babatunde, Ojo Olusola E., Osibanjo Adetola Adetokunbo, Elemo Gloria N. Influence of Coconut Fibre Inclusion on Rheological Properties of Composite Wheat-Cassava Flour Dough Using the Mixolab. Journal of Food and Nutrition Sciences. Vol. 3, No. 6, 2015, pp. 229-235. doi: 10.11648/j.jfns.20150306.15

\begin{abstract}
Coconut (Cocos nucifera) is one of the tropical nut fruits containing high percentage of dietary fibre among plant foods that are beneficial to human health. Rheological characteristics measurements for wheat cassava flour blends with the inclusion of coconut fibre were studied using the Mixolab, the standard "Chopin+"protocol. The flour blends were substituted with different levels of coconut fibre $(0 \%, 5 \%, 10 \%$, and $15 \%)$ and wheat-cassava flour blend was used as control. The effects of added coconut fibre on the rheological properties of composite dough of wheat and cassava $(90: 10 \mathrm{w} / \mathrm{w})$ were evaluated. The maximum torque during mixing $(\mathrm{C} 1)$, the protein weakening based on the mechanical work and temperature $(\mathrm{C} 2)$, the starch gelatinization (C3), the stability of the starch gel formed (C4), the starch retrogradation during the cooling stage (C5) were determined. Results showed that the torque values in all the dough decreased with the inclusion of fibre except in CI and $\mathrm{C} 2$. The values of $\mathrm{C} 1$ and $\mathrm{C} 2$ (the dough development and the stability of proteins) increased with the increasing level of coconut fibre. Increasing level of fibre inclusion reduces the gelatinization of the cooked starch (C3), however 5\% fibre dough (CNF) had the highest torque and the lowest torque was observed in 15\% fibre dough (FPC), though the control sample (CTR) non fibre dough had the highest $2.15 \mathrm{Nm}$. Addition of fibre increased the dough stability from 6.60 to 8.58 minutes. It was observed that $15 \%$ fibre enriched (FPC) had the highest dough stability.
\end{abstract}

Keywords: Coconut Flour, Composite Flour, Mixolab, Rheological Properties, Dough Stability

\section{Introduction}

Coconut (Cocos nucifera) belongs to the family Aracacea. It is a versatile fruit with many uses and it is widely distributed throughout the tropics and subtropics [1]. Coconut grows in more than 90 countries of the world, with a total production of 62 million tonnes per year, however most of the world production is in tropical Asia [2]. Coconut fibre is from coconut residue, which is a by- product of coconut milk extraction. It is a naturally available good source of dietary fibre, low in digestible carbohydrates and free of trans fatty acid, hence its utilization as functional food ingredients for human consumption. In recent times, the addition of fibre to foods has gained popularity as a result increasing incidence of some diet related diseases. Recent studies indicated that dietary fiber may prevent some health condition and diseases such as constipation, hemorrhoids, hypercholesterolemia and colorectal cancer $[3 ; 4]$.

Rheological properties of dough are very important indices for product development in terms of product quality and process efficiency [5-8]. During the baking process, flour composites are subject to mechanical work and heat treatment that promote changes in their rheological properties [9]. The unique dough-forming and breadmaking property of wheat is attributed to gluten protein, which is formed when wheat flour is hydrated and subjected to mechanical shear. Substitution of wheat flour with nonwheat flour and fibre has been reported to reduce bread making potentials of wheat flour due to dilution and disruption of the rheological and mechanical properties of gluten [10-11], while on the other hand report showed that 
addition of fibre can also improve technological properties of dough such as prevention of syneresis and modification of viscosity and texture of formulated foods [12-13]. Dietary fibers in foods particularly in baked products have been reported to cause undesirable results such as weak dough in breadmaking, poor viscoelastic property [14-17]. The influence of fiber from various cereals including rice bran on the rheological characteristic of dough from wheat flour on the quality of biscuit has been studied [18].

The Mixolab, device (introduced in 2004 by Chopin Technologies, accepted as the ICC standard method No. 173) is one of the latest test equipments used to determine the rheological quality of dough. It allows the characterization of the physicochemical behavior of dough when subjected to a dual mixing and temperature constraints. It measures in real time the torque (expresses in $\mathrm{Nm}$ ) produced by mixing the dough between two kneading arms, where the dough is subjected to dual mixing and temperature constrains $[6 ; 19-$ 20]. The Mixolab technique allows the study of rheological parameters of flour in terms of $(i)$ proteins quality by determining their water absorption, stability, elasticity, andweakening properties; (ii) starch behaviour during gelatinisation and retrogradation; (iii) consistency modification when adding additives, and (iv) enzymatic activity of proteases, amylases, etc $[19 ; 21]$. The Mixolab works with a constant dough weight to eliminate variation and ensure uniformity during mixing. It is also efficient in determining the rheological properties and developing products high in fibre regardless of their type or granulometry.

Several studies have been carried out to investigate the application of Mixolab in rheological testing of gluten-free flours, whole wheat flour and bran, and effect of different hydrocolloids and enzymes on the rheological behavior of flour [6;22-23]. It's potential to determine the rheological behaviour of bread dough from white flour and whole meal was investigated [21]. Also, the device was explored to characterize the thermo-mechanical behaviour of wheat flours and to establish the correlations within rheological parameters of the wheat flour supplemented with different additives such as fungal $\alpha$-amylase, fungal hemicellulase and fungal xylanase [24].

Therefore, this present study is aimed at investigating the effect of coconut fibre on the rheological properties of composite wheat-cassava flour blends using the Mixolab.

\section{Materials \& Methods}

\subsection{Source of Raw Materials}

The Wheat Flour (WF) used was commercial baker's grade wheat flour milled by Nigeria Flour Mills (Golden Penny, Nigeria). High Quality Cassava flour was procured from Federal Institute of Industrial Research Oshodi pilot plant, Lagos Nigeria while the coconut used was also procured from a local market in Lagos, Nigeria.

\subsection{Methods}

Coconut fruits were sorted and processed to extract coconut milk and the resulting shaft/residue was washed thoroughly with boiling water to enhance complete removal of milk and oil from the shaft. It was drained, dried and ground using a grinder (model HL 3294/C Phillips) to obtain fine particles. The coconut fibre obtained was mixed with the composite flour of cassava and wheat at ratio 10:90 (w/w) at different level of inclusion $(0 \%, 5 \%, 10 \%$ and $15 \%)$. All the measurements were performed using the Mixolab "Chopin+" protocol.The preparation and characterization of the dough was according to the standard method(ICC-Standard Method No. 173, 2006; AACC 54-60.01; adapted ISO 5530-1:1997). Dough rheological investigations were performed by Mixolab with the standard settings shown in Table I which simultaneously determines dough characteristics during the processof mixing at constant temperature, as well as during the period of constant heating and cooling.

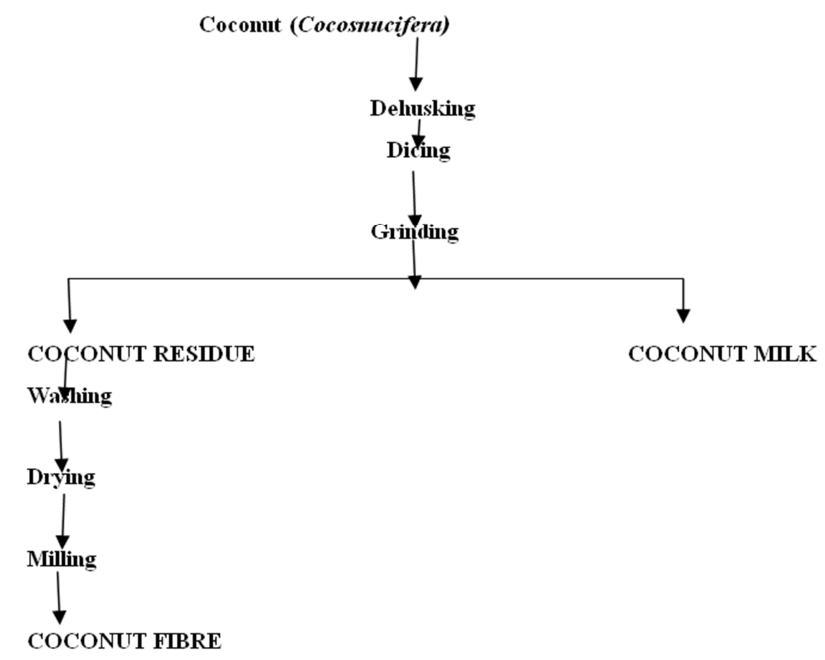

Figure 1. Flow chart for the production of coconut fibre.

This characteristic torque/time/temperature curve is divided into five distinct and important phases corresponding to the following:

$\mathrm{C} 1(\mathrm{Nm}$ - maximum torque $(1.1 \pm 0.05 \mathrm{Nm})$ during mixing;

$\mathrm{C} 2(\mathrm{Nm})$ - first minimum point on the curve and measures protein weakening based on the mechanical work and temperature;

$\mathrm{C} 3(\mathrm{Nm})$ - this is second maximum on the curve and it indicates starch gelatinization;

$\mathrm{C} 4(\mathrm{Nm})$-is the second minimum point indicating the stability of the starch gel formed and amylase activity.

C5 $(\mathrm{Nm})$-is the last point on the curve and measures the starch retro gradation during the cooling stage;

$\alpha$ - represents the slope of the curve between the end of the period of $30^{\circ} \mathrm{C}$ and $\mathrm{C} 2$; gives indication about the rate of the proteins thermal weakening;

$\beta$ - Represents the slope of the curve between $\mathrm{C} 2$ and C3; gives indications about the gelatinization rate;

$\gamma$ - Represents the slope of the curve between $\mathrm{C} 3$ and C4; gives indications about the rate of amylase activity. 


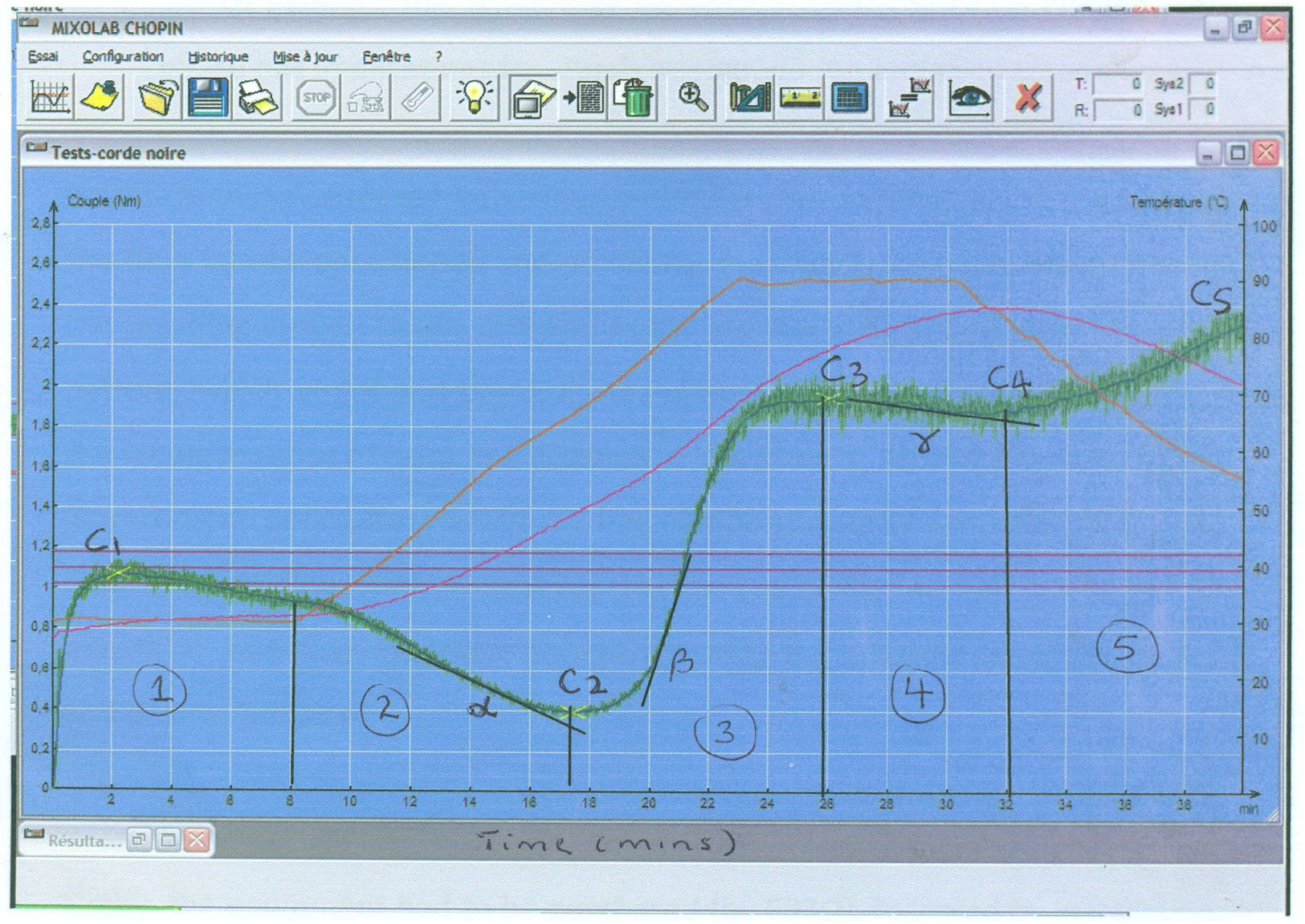

Figure 2. A standard Mixolab curve.

Table 1. Setting of the Mixolab.

\begin{tabular}{lc}
\hline Parameter & Value \\
\hline Mixing rate $(\mathrm{rpm})$ & 80 \\
Dough weight $(\mathrm{g})$ & 75 \\
Tank temperature $\left({ }^{\circ} \mathrm{C}\right)$ & 30 \\
Total analysis time $(\mathrm{min})$ & 45 \\
\hline
\end{tabular}

Table 2. Percentage Composite Flour Formulation.

\begin{tabular}{|c|c|c|c|c|}
\hline \multirow{2}{*}{ Flour blends } & \multicolumn{4}{|c|}{ \% LEVEL OF COCONUT FIBRE INCLUSION } \\
\hline & $\mathbf{0}$ & 5 & 10 & 15 \\
\hline Wheat flour & 90 & 85 & 80 & 75 \\
\hline Cassava flour & 10 & 10 & 10 & 10 \\
\hline Coconut fibre & 0 & 5 & 10 & 15 \\
\hline
\end{tabular}

Key: 0\%--------CTR, 5\%---------CNF, 10\%---------CTP, 15\%----------PPC

\section{Results and Discussion}

\subsection{Rheological Characteristics}

The results obtained from Mixolab measurement of dough are presented in Table 3. The $\mathrm{C} 1$ figures were all within the stipulated range of $1.10 \pm 0.05 \mathrm{Nm}$ and it is a constant temperature period at the start of the test, in which dough characteristics during mixing are measured.
C2 gives indication about the dough weakening due to protein unfolding which is coupled with torque increase. It ranged from $0.32-0.44 \mathrm{Nm}$. Coconut fibre is from vegetable which does not have gluten at all. The dough substitution with coconut fibre changed dough elasticity significantly during mixing and heating $(\mathrm{p}<0.05)$ significantly. As the level of fibre inclusion increases, the more is the thermal protein network weakening, hence the dilution effect of the fibre on the dough which consequently reduced the dough consistency. However, the control sample (CTR) non fibre dough had $0.36 \mathrm{Nm}$.

The values of $\mathrm{C} 1$ and $\mathrm{C} 2$ (the dough development and the stability of proteins) increased with the addition of coconut fibre, but the greatest increase is in $15 \%$ level of inclusion.

C3 indicates starch gelatinization, this is referred to the cooking and the heating stage which describes the starch behavior and it is characterized by the gelatinized ability of the starch. It ranged from 1.59-1.47 Nm.

Results showed that the torque values in all the dough decreased with the inclusion of fibre. Increasing level of fibre inclusion reduces the gelatinization of the cooked starch, however 5\% fibre dough (CNF) has the highest torque and the lowest torque was observed in $15 \%$ fibre dough (FPC), while the control sample (CTR) non fibre dough had the highest $2.15 \mathrm{Nm}$. These results are in accordance with the results of [25] that used wheat bran from $3-30 \%$. 
The amylase activity and the physical breakdown of the starch granules are associated with a reduction in the viscosity in the fourth stage. The torque $\mathrm{C} 4$ gives indication about the rate of enzymatic hydrolysis and the $\mathrm{C} 4$ dough's values showed a decrease in value from $5 \%$ to $10 \%$ fibre inclusion, but at $15 \%$ fibre inclusion an increase in $\mathrm{C} 4$ value was observed. This irregular trend could be due to the fact that coconut fibre is not from grain mantle that contains large quantity of $\alpha$ - amylases that is actually responsible for reduction of $\mathrm{C} 4$ values.

The torque (C5) is an indication of retrogradation. It decreased with the addition of fibre from the CTR -control sample $(2.28$ to $0.00 \mathrm{Nm})$ to $10 \%$ fibre inclusion (CTP). The dough with $15 \%$ of coconut fibre (FPC) is the strongest with
$2.11 \mathrm{Nm}$ amongst the fibre enriched dough during starch retrogration time in the cooling period. This was in accordance to the results of [26] that have enriched flour with different fiber, like fibrulin, fiberx, exafine and swelite, in various reports. Report showed that fibre inclusion implied better shelf life.

Amplitude: This is the curve width at $\mathrm{C} 1$ and indicates protein quality or elasticity of the dough. The higher the figure, the more elastic is the dough. It varies from 0.09-0.13 $\mathrm{Nm}$ with the highest value in $15 \%$ fibre enriched (FPC).

Development time and stability values are indicators of flour strength, thus higher values suggesting performance of stronger dough when coconut fibre is added.

Table 3. Mixolab Characteristics of the Composite Dough Blends.

\begin{tabular}{|c|c|c|c|c|c|c|c|c|c|c|c|}
\hline \multirow{2}{*}{$\begin{array}{l}\text { Sample } \\
\text { code }\end{array}$} & C1 & $\mathrm{C2}$ & C3 & $\mathrm{C} 4$ & $\mathrm{C5}$ & $\alpha$ & B & $r$ & \multirow{2}{*}{$\begin{array}{l}\text { Amplitude } \\
\text { (Nm) }\end{array}$} & \multirow{2}{*}{$\begin{array}{l}\text { Stability } \\
\text { (min) }\end{array}$} & \multirow{2}{*}{$\begin{array}{l}\text { WA } \\
(\%)\end{array}$} \\
\hline & & & $(\mathrm{Nm})$ & & & $(\mathrm{Nm} / \mathrm{min})$ & $(\mathrm{Nm} / \mathrm{min})$ & $(\mathrm{Nm} / \mathrm{min})$ & & & \\
\hline $\mathrm{CNF}$ & 1.08 & 0.32 & 1.59 & 1.28 & 1.70 & -0.05 & 0.238 & -0.046 & 0.09 & 6.60 & 73.2 \\
\hline СТP & 1.09 & 0.37 & 1.51 & 0.31 & 0.00 & -0.082 & 0.408 & -0.838 & 0.09 & 7.93 & 71.2 \\
\hline FPC & 1.15 & 0.44 & 1.47 & 0.51 & 2.11 & -0.084 & 0.294 & -0.172 & 0.13 & 8.58 & 70.9 \\
\hline CTR & 1.13 & 0.36 & 2.15 & 1.83 & 2.28 & -0.01 & 0.574 & -0.026 & 0.09 & 1.80 & 60.9 \\
\hline
\end{tabular}

* Values are means of triplicate determinations

Key: CNF-5\% Coconut inclusion, CTP-10\% Coconut inclusion, FPC- 15\% Coconut inclusion and CTR-No coconut inclusion

\subsection{Effect of Coconut Fibre on Dough Stability}

Dough stability is the time (in minutes) when the torque exceeds $\mathrm{C} 1$ and is a measure of dough resistance to kneading. The higher the figure, the stronger is the dough. Results showed that with increasing level of fibre addition, dough stability increases (Fig 5). Inclusion of fibre increases the dough stability from 6.60 to 8.58 minutes, while the control sample has 1.80 minutes. It was observed that $15 \%$ fibre enriched (FPC) had the highest dough stability. This is as a result of increased interaction of hydrogen connections including hydroxides groups present in fibre molecules. Dough stability is related to the quality of the protein matrix, which is easily damaged by the incorporation of other ingredients [27]. The results are in accordance with the results of other researchers that have used different types of fibers [17]

\subsection{Effect of Coconut Fibre Inclusion on Dough Water Absorption (\%)}

Water absorption is the quantity of water required to obtain $\mathrm{C} 1=1.1 \pm 0.05$. It ranged from $60.9-73.2 \%$ with the highest value in 5\% fibre inclusion (CNF) and the lowest in the control sample (CTR) which is the non fibre enriched flour blends (Fig 5 ). It decreases with increased level of fibre inclusion from $5 \%-15 \%$. Water absorption is an important dough property as it has effect on bread quality and its shelf life.

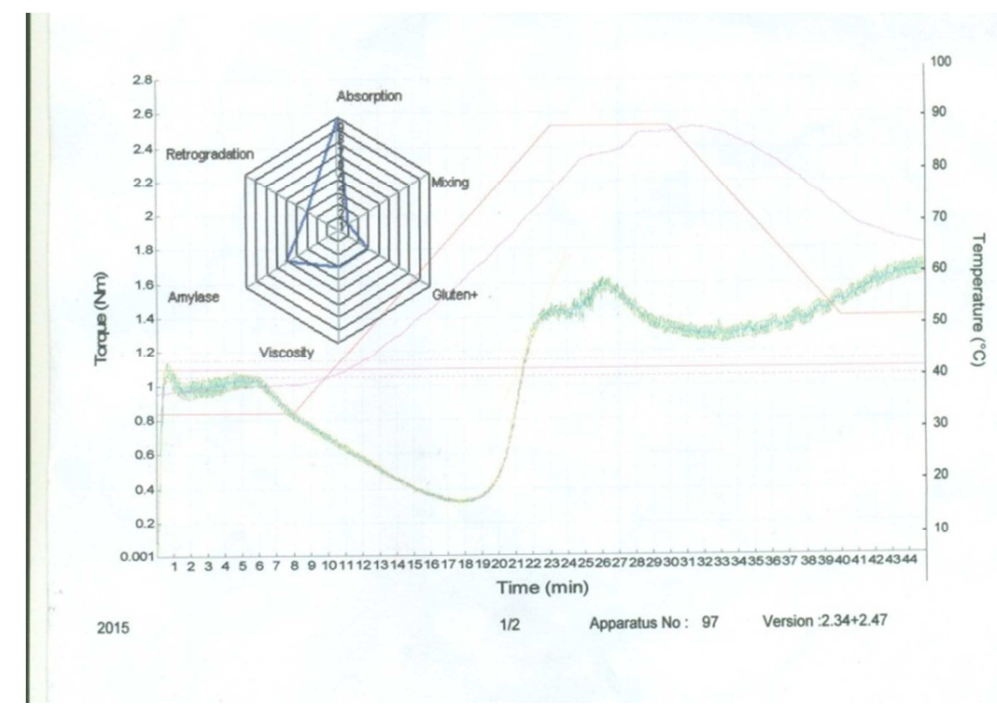

$5 \%$ coconut fibre dough $(\mathrm{CNF})$ 


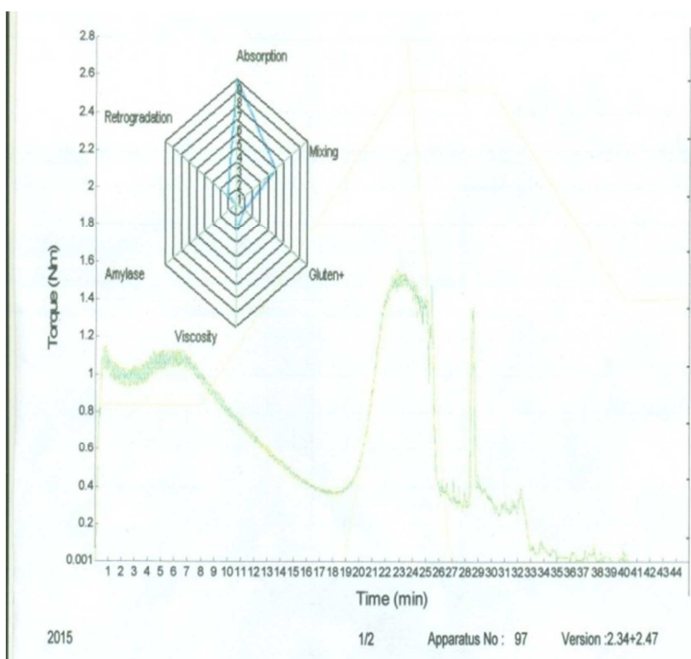

$10 \%$ coconut fibre dough (CTP)

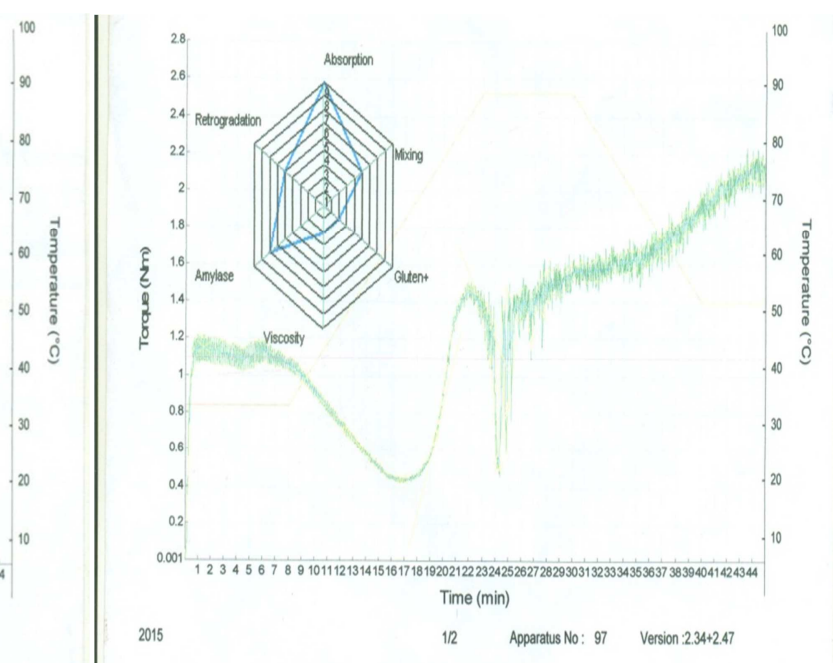

$15 \%$ coconut fibre dough (FPC)

Figure 3. Mixolab curves of analyzed dough samples.

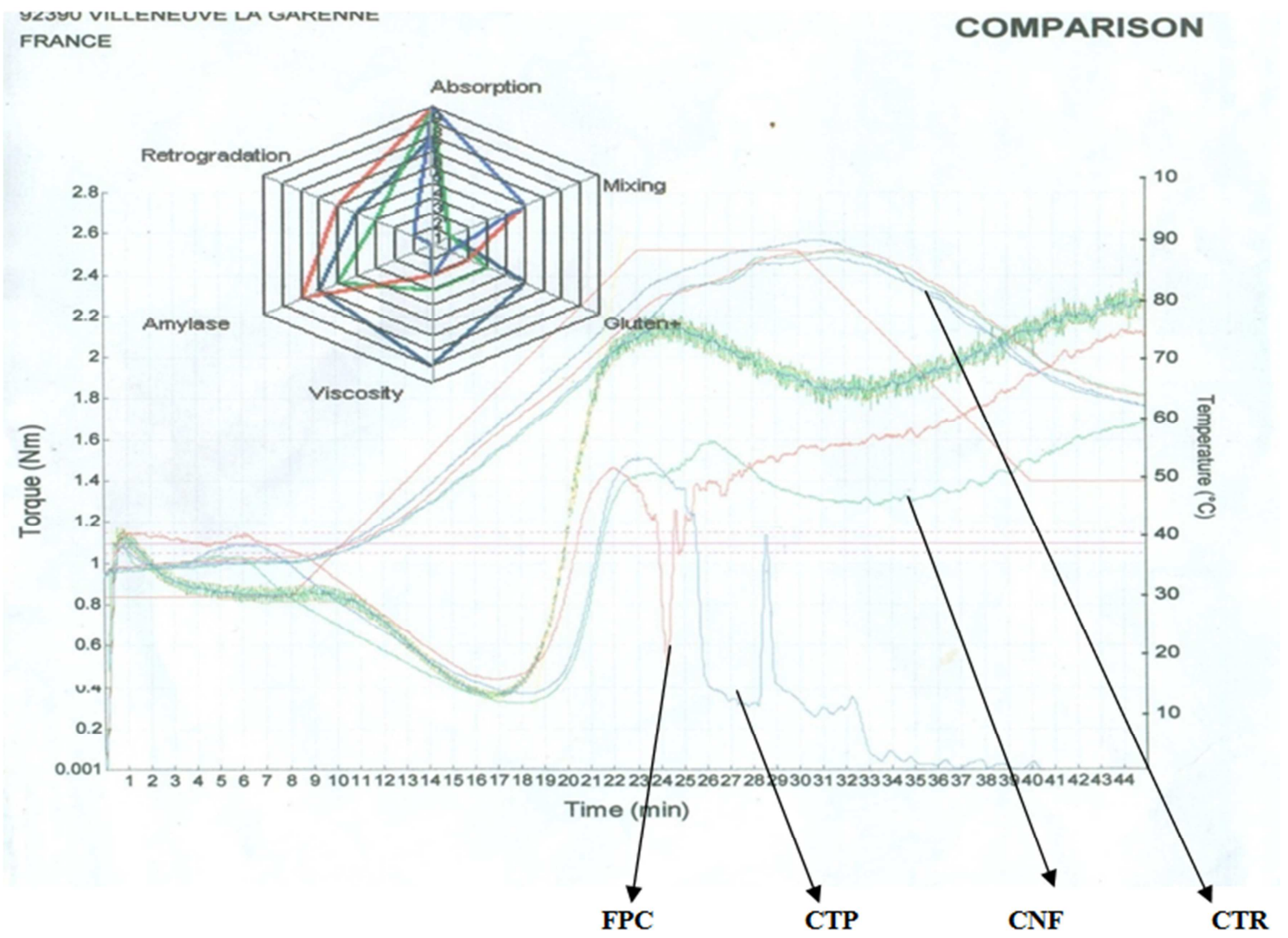

Figure 4. Mixolab curves obtained for different levels of coconut fibre dough.

\section{Conclusion}

The Mixolab is a new equipment which measures the dough torque associated with mixing and temperature constraints and it is noteworthy that this Mixolab can be used as a substitute to other quality tests to envisage the protein and starch properties within a short period of time of 45 minutes, as well as an efficient equipment to predict the bread making quality of wheat flours based on dough stability and $\mathrm{C} 2$ values. It was observed from the results that the influence of coconut fibre on the composite flour was significant leading to a weakening of the gluten network of the dough with good effects on its rheological properties. This study revealed that the higher the level of coconut fibre addition, the lower the dough water absorption, with $15 \%$ fibre- enriched dough (FPC) having the lowest water absorption value(70.9\%) and increased level of fibre addition resulted in increased dough stability from 6.608.58 minutes with $15 \%$ fibre- enriched dough (FPC) having the highest dough stability. 


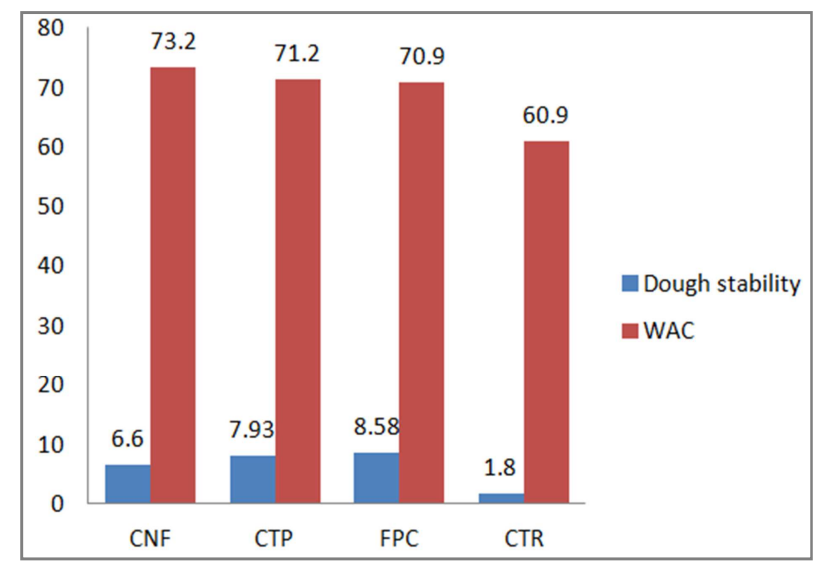

Key: CNF---5\% Coconut fibre, CTP----10\% Coconut fibre, FPC----15\% Coconut fibre, CTR---- $0 \%$ Coconut fibre

Figure 5. Effect of coconut inclusion on dough stability(mins) \&water absorption (\%).

\section{References}

[1] James A. Duke, Handbook of Energy Crops, unpublished (1983). "Cocos nucifera L.".Purdue University, NewCROP, the New Crop Resource Online Program.

[2] Food And Agriculture Organization of the United Nations. Economic and Social Department.Statistics Division. (September 2, 2010). FAOSTAT - Production - Crops [Selected annual data]. Retrieved January 24, 2015 from the FAOSTAT Database.

[3] Fernández-López, J., Fernández-Ginés, J. M., AlesonCarbonell, L., Sendra, E.,SayasBarberá, E. and Pérez-Álvarez, J. A. (2004). Application of functional citrus by-products to meat products. Trends Food Sci. Technol. 15: 176- 185.

[4] Trinidad, P.T., Mallillin, A.C., Valdez, D.H., Loyola, A.S., Askali-Mercado, F.C., Castillo, J.C., Encabo, R.R., Masa, D.B., Maglaya, A.S. and Chua, M.T. (2006), Dietary fiber from coconut flour: A functional food. Innovative Food Science and Emerging Technologies, 7: 309-317.

[5] Collar C., Armero E., (1996): Physico-chemical mechanisms of bread staling during storage: Formulated dough's as a technological issue for improvement of bread functionality and keeping quality. Recent ResearchDevelopments in Nutrition, 1, pp. 115-143.

[6] Rosell C.M., Collar C., Haros M. (2007): Assessment of hydrocolloid on the thermomechanical properties of wheat using the mixolab. Food Hydrocolloids, 21: 452-462.

[7] Mondal A, Datta AK. (2008): Bread baking A review. J Food Eng. 86: 465-74.

[8] Moreira, R., Chenlo, F., Torres, M.D., Prieto, D.M., (2010): Influence of the particle size on the rheological behavior of chestnut flour dough. Journal ofFood Engineering, 100, pp. 270-277.

[9] Bollaín C., Collar C.(2004): Dough viscoelastic response of hydrocolloid /enzyme/surfactant blends assessed by uni-and bi-axial extension measurements., Food Hydrocolloids, 18: 499-507.
[10] Schoenlechner R, Szatmari M, Bagdi A, Tömösközi S (2013). Optimisation of bread quality produced from wheat and proso millet (Panicummiliaceum L.) by adding emulsifiers, transglutaminase and xylanase. LWT - Food Sci. Technol. 51: 361-366.

[11] Ribotta PD, Arnulphi SA, León AE, A-ón MC (2005).Effect of soybean addition on the rheological properties and breadmaking quality of wheat flour. J. Sci. Food Agric. 85: 1889-1896.

[12] Lario, Y., E. Sendra, J. Garcia-Perez, C. Funentes, E. SayasBarbera, J. Fernandez-Lopez and J.A. Perez-Alvarez, 2004. Preparation of high dietary fiber powder from lemon juice byproducts.Innovative Food Sci. Emerg.Technol.

[13] Grigelmo-Migeul, N. and O. Martin-Belloso, (1998). Characterization of dietary fiber from orange juice extraction. Food Res. Int., 31: 355-361.5: 113-117.

[14] GafurXhabiri.,ToniAcoski., MarijaStanojeska., ValbonaSinani, (2013)The assessment of rheological Qualities with the mixolab of different wheat flours enriched with their bran.

[15] Abdalla S. Ammar, Samir A. Salem and Farid H. Badr (2011) Rheological Properties of Wheat Flour Dough as Affected by Addition of Whey and Soy Proteins Pakistan Journal of Nutrition 10 (4): 302-306, ISSN 1680-5194.

[16] GhufranSaeed SM, SaqibArif, Mubarak Ahmed, Rashida Ali, Fred Shih (2009): Influence of rice bran on rheological properties of dough and in the new product development $J$ Food SciTechnol 2009, 46(1), 62-65.

[17] Gomez M, Ronda F, Blano CA, Caballero PA, Apesteguia A (2003). Effect of dietary fiber on dough rheology and bread quality. European Food Res Technol 216: 51-56.

[18] Sudha ML, Vetrimani R, Leetavathi K (2007). Influence of fiber from different cereal on the rheological characteristic of wheat flour dough and on biscuit quality. Food Chem 100: 1365-1370.

[19] Kahraman K, Sakyyan O., Ozturk S., Koksel H., Sumnu G, Dubat A. (2008): Utilization of Mixolab1 to predict the suitability of flours in terms of cake quality. European Food Research Technology, 227: 565-570.

[20] Ozturk S., Kahraman K., Tiftik B., Koksel H. (2008): Predicting the cookie quality of flours by using Mixolab. European Food Research Technology, 227: 1549-1554.

[21] Collar C., Bollain C., Rosell C.M. (2007): Rheological behaviour of formulated bread doughs during mixing and heating. Food Science and Technology International, 13: 99107.

[22] Ghodke, S. K. and Laxmi, A. (2007).Influence of Additives on Rheological Characteristics of Whole-wheat Dough and Quality of Chapatti (Indian Unleavened Flat Bread).Part 1. Hydrocolloids.FoodHydrocol.,21: 110-117.

[23] Haros M., Ferrer A., Rosell C.M. (2006).Rheological behaviour of whole wheat flour, In: IUFoST - World Congress 13th World Congress of Food Science \& Technology. DOI 10. 1051/UFoST: 20060681.

[24] Banu, I., Stoenescu, G., Ionescu, V., Aprodu, I. (2011). Estimation of the baking quality of the wheat flours based on rheological parameters of the mixolab curve. Czech Journal of Food Science, 29(1), 35-44. 
[25] Banu J., Stoenescu G., Ionescu S.V(2012): Effect of the addition of wheat bran stream on dough rheology and bread quality, The Annals of theUniversity Dunarea de Jos of Galati, Fascicle VI-Food Technology 36 (1)39-52. European journal of scientific research 2013 edition vol.9, No.24 ISSN: 1857 7881 (Print) e - ISSN 1857- 7431.

[26] Rosell M.C., Santos E., Collar C, (2010): Physical characterization of fiber enriched bread doughs by dual mixing and temperature constraint using the Mixolab, European Food Research and Technology Vol. 231, Issue 4, pp 535-544.

[27] Gomez M., Gonzalez J.,Oliente B.(2012): Effect of extruded wheat germ on dough rheology and bread quality. Food Bioproc Technol, DOI: 10.1007/s11947-011-0519-5 (in press). 